\title{
THE EFFECT OF UNCERTAINTY IN A FUZZY INPUT-OUTPUT ANALYSIS OF WATER CONSUMPTION APPLIED TO MACEDONIA ${ }^{1}$
}

\author{
Jordan HRISTOV ${ }^{2,3}$, Yves SURRY 4
}

Received October 19, 2013; accepted November 10, 2013. Delo je prispelo 19. oktobra 2013, sprejeto 10. novembra 2013.

\begin{abstract}
The effect of uncertainty in a fuzzy Input-Output analysis of water consumption applied to Macedonia

This paper reconsiders the reliability of the results obtained by Hristov et al. (2012) from the input-output analysis of water consumption, by taking into account the effect of uncertainty inherent in the data. The imprecision and uncertainty is studied within a workable fuzzy environment as introduced by Beynon et al. (2005), where rank reversal is plausible. In addition, the water-intensive structure of the Macedonian economy is investigated by applying Dietzenbacher eigenvector methodology (1992). As suggested in the analysis of Hristov et al. (2012), the water-intensive structure of the economy in Macedonia is confirmed as being mainly focused on agriculture and several industrial sectors, given that rank reversal is absent. Consequently, there is a need to introduce changes in the agricultural production technology as well as the specialization of production in this region.
\end{abstract}

Key words: agriculture / industry / water consumption / analyses / Macedonia

\section{INTRODUCTION}

As we become more and more aware of certain issues and realize their complexity, there is an increase in the number of phenomena about which we are uncertain. To reduce this uncertainty, we often tend to collect more information, but sometimes the required information is not available and consequently the uncertainty increases even more.

Uncertainty is a topic that generally requires tak-
Ocena nezanesljivosti fuzzy input-output analize porabe vode v Makedoniji

Prispevek obravnava zanesljivost rezultatov input-output analize porabe vode $\mathrm{v}$ študiji Hristov in sod., 2012, ob upoštevanju nezanesljivosti podatkov. Nenatančnost in nezanesljivost podatkov proučujemo $\mathrm{z}$ uporabo »fuzzy« metodologije, ki so jo uvedli Beynon in sod. (2005) in omogoča spremembo rangov. Intenzivno strukturo porabe vode $\mathrm{v}$ makedonskem gospodarstvu proučujemo z uporabo metodologije Dietzenbacherjeve »eigenvektor « metodologije (1992) za porabo vode. Podobno kot v predhodni analizi Hristova in sod. (2012) smo brez spremembe rangov potrdili strukturo porabe vode $\mathrm{v}$ Makedoniji, ki je v glavnem osredotočena na kmetijstvo in nekatere industrijske panoge. Posledično morajo odločevalci pazljivo pretehtati spremembe v kmetijskih proizvodnih tehnologijah in proizvodnih usmeritvah v regiji, ali pa razmisliti o spremembi politike cen vode.

Ključne besede: kmetijstvo / industrija / voda / poraba vode / analize / Makedonija

ing steps to improve our knowledge and deserves more detailed investigation. Complexity combined with uncertainty may be defined as fuzziness (Cao, 2010). Since the introduction of fuzzy logic and fuzzy set theory in the 1960s, this concept has been implemented in many fields of economics including input-output analysis (Morillas et al, 2011). Indeed, the notion of fuzziness and its application allows some flexibility in "processing" the observed data at a given level, where uncertainty and imprecision are reduced. This is achieved by consider-

1 Macedonia's constitutional name is the Republic of Macedonia and, within the United Nations system, this country is being provisionally referred to as "the former Yugoslav Republic of Macedonia - FYROM” (UNSC Resolution 817/1993)

2 Swedish Univ. of Agricultural Sciences, Dept. of Economics, Johan Brauners väg 3, 756 51-Uppsala, Sweden

3 Corresponding author, e-mail: jordan.hristov@slu.se

4 Same address as 2, e-mail: yves.surry@slu.se 
ing a membership function for each observed object being studied, with the result that the final outcome in the analysis depends entirely on the chosen level of flexibility (Zadeh, 1965). Several studies including, among others, Buckley (1989), Beynon et al. (2005), Beynon \& Munday (2006) and Diaz et al. (2006), have recently applied fuzzy logic and fuzzy theory to input-output analysis, not only to assess the importance (ranking) of economic sectors and their interdependencies, but also to investigate environmental and sustainability problems (carbon footprint analysis).

In this context, we can justify applying a fuzzy approach to study the consumption of water in Macedonia on the grounds that several data problems are becoming apparent in this country's input-output table and its water accounts. To illustrate this point, we note that different data sources (EUROSTAT and the State Statistical Yearbook of Macedonia) give rise to different figures concerning the available supplies of water for several economic sectors. Moreover, aggregating primary factors returns among sectors is an additional source of uncertainty and imprecision in input-output analysis (Beynon \& Munday, 2008). Due to the absence of data on water consumption in some sectors, the initial input-output table of Macedonia, which covers 59 sectors, needs to be aggregated into 28 sectors. Hence, apart from the uncertainty associated with the data used to construct the water accounts, another source of uncertainty may stem from aggregation bias.

Previous studies by the authors (Hristov et al, 2012) have shown that agriculture, mining and some industrial sectors, including mainly base metals, are the key water consuming industries in Macedonia. Given the uncertainties arising from data problems and aggregation as highlighted above, it is crucial to investigate the waterintensive structure of the Macedonian economy using an approach based on fuzzy input-output modelling. For this purpose, inter-industry linkages in terms of water used are assessed using backward and forward linkage indicators based on the eigenvector procedure developed by Dietzenbacher (1992). The main incentive for adopting this approach is that some of the key water use sectors identified by Hristov et al., 2012 using the Rasmussen methodology were not considered in sufficient detail during the analysis of intersectoral water relationships and the derived indicators. Since Dietzenbacher (1992) demonstrated that his method is superior to the Rasmussen methodology, we can assume it would provide a better indicator of interindustry linkages than the method applied by Hristov et al, (2012). In the present study, we apply the fuzzy environment or approach to key water consuming sectors that are identified through the analysis of inter-sectoral linkages. Hence, as a result of the reduced imprecision and uncertainty, we expect that our findings may contribute to raising awareness for better water resource management to achieve sustainable development of the country.

This paper is organized as follows. Section two gives an overview of the methodology framework used to investigate imprecision and uncertainty in input-output analysis. The fundamentals of the analysis are presented in section three along with a discussion, along with more details on the linkage analysis and the fuzzy approach. After considering the pattern of intensive water consumption in Macedonia from different perspectives in terms of uncertainty and imprecision, we offer a brief conclusion.

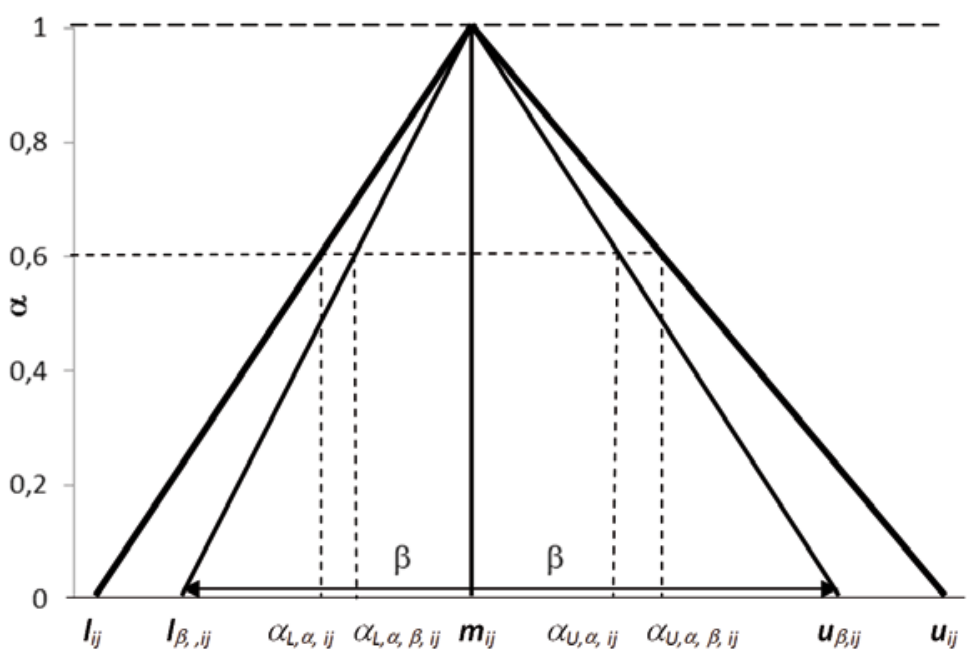

Figure 1: Triangular membership function based on $(l, m, u)$ values and the $\alpha$ and $\beta$ parameters (Beynon et al., 2005) Slika 1: Trikotna vključitvena funkcija, ki temelji na $(l, m, u)$ vrednostih in parametrih $\alpha$ in $\beta$. (Beynon in sod., 2005) 


\section{METHODOLOGY}

\subsection{FUZZY INPUT-OUTPUT FRAMEWORK}

A fundamental aspect of input-output analysis is the identification of key sectors in terms of their buyer and supplier linkages. Being irrespective of the buyer-seller relationship based on using the inverse of Leontief's model to search for the key sector, the uncertainty and imprecision associated with the direct (input-output) technical coefficients affect the procedure for identifying key sectors. However, the fuzzy environment allows us to overcome this problem.

The main advantage of fuzzy logic and fuzzy set theory is that it enables us to assign a membership function to each object in the analysis. This means that there is no sharp boundary or value for the object, which depends entirely on the defined membership function $\bar{a}$. In our study, we introduce a fuzzy triangular membership function which depends on three values: lower $(l)$, middle $(m)$ and upper $(u)$, i.e. $\bar{a}=[l, m, u]$ (Fig. 1). The $\alpha$-cut ranging from 0 to 1 has an effect over the membership function by closing the triangular number to an interval $\left[a_{l, \alpha}, a_{u \alpha}\right]$, whereas the $\beta$ value, also ranging from 0 to 1 , represents the level of imprecision as the proportional distance between the $l$ and $u$ values relative to $m$ (Beynon $\&$ Munday, 2008). The larger the $\beta$ value, the greater the imprecision, i.e. $\beta=1$ indicates the worst imprecision case (ibid).

Although we omit here the overview on fuzzy set theory outlined in Zadeh (1965), we nevertheless stress the great importance of how the triangular membership functions of each fuzzy number are defined. A fuzzy number is a convex fuzzy subset of a real number $R$, represented by its triangular membership function (Wang et al., 2006):

$$
\bar{a}(x)=\left\{\begin{array}{ll}
\frac{x-l}{m-l}=\bar{a}_{L} & \text { if } l \leq x \leq m \\
\frac{x-u}{l-u}=\bar{a}_{U} & \text { if } m \leq x \leq u
\end{array}\right\}
$$

where the triangular uncertain set $\bar{a}=[l, m, u]$ has an inverse membership function:

$$
\bar{a}^{-1}(\alpha)=\left\{\begin{array}{lr}
(1-\alpha) l+\alpha m=\bar{a}_{L}^{-1} & \text { if } o \leq \alpha \leq 1 \\
(1-\alpha) u+\alpha m=\bar{a}_{U}^{-1} & \text { if } 0 \leq \alpha \leq 1
\end{array}\right\}
$$

Although the $\alpha$-cut ensures that the membership function has a closed set, the $\beta$ proportion value plays a more important role in the fuzzy environment. By introducing the $\beta$ parameter, we can ensure the existence of a solution as well as the certainty of the correctness of the fuzzy input-output model (Buckley, 1989; Beynon \& Munday, 2007). In other words, the constraint $\sum_{i=1}^{s} u_{i j}<1$ for $s$ number of sectors should be satisfied. In a fuzzy environment, when the imprecision is maximal, i.e. $\alpha=0$, this constraint becomes:

$$
\sum_{i=1}^{s} m_{i j}+\beta\left(u_{i j}-m_{i j}\right)<1
$$

Solving for $\beta$, it can be seen that the parameter has a domain between 0 and 1, i.e:

$$
\beta<\frac{1-\sum_{i=1}^{s} m_{i j}}{\sum_{i=1}^{s}\left(u_{i j}-m_{i j}\right)}
$$

Hence, the allowed upper bound on $\beta$ that ensures a solution to the fuzzy input-output matrix, defined as $\beta_{\text {max }}$ can be written as follows:

$\beta_{\max }=\min \left(1, \frac{1-\sum_{i=1}^{s} m_{i 1}}{\sum_{i=1}^{s}\left(u_{i 1}-m_{i 1}\right)}, \frac{1-\sum_{i=1}^{s} m_{i 2}}{\sum_{i=1}^{s}\left(u_{i 2}-m_{i 2}\right)}, \ldots, \frac{1-\sum_{i=1}^{s} m_{i s}}{\sum_{i=1}^{s}\left(u_{i s}-m_{i s}\right)}\right)$

As a consequence of the previously outlined definition of $\beta$, although the upper bound of 1 is a general condition, it may sometimes not be strictly required (Beynon et al. 2005). This is found to be the case in our application to the Macedonian economy.

In common with most of the existing literature by Beynon and others, we adopt a general symmetric imprecision with $l=0$ and $u=2 \mathrm{~m}$. This choice is mainly based on computational simplicity. However, according to Diaz \& Morrillas (2011), the proposed framework is strongly criticized because this form of the membership function is considered as unrealistic and arbitrary. In addition, the assigned upper value, which is twice the observed $(m)$, leads to the possibility that some of the direct technical coefficients may be higher than 1 . However, the introduction of the $\beta$ parameters corrects this problem and ensures that it has a solution. Using the initial symmetric limits does not necessarily mean that the triangular membership functions will remain consistently symmetric (normal triangle) as the level of imprecision $(\beta)$ increases. In other words, as the level of imprecision increases to the value ensuring a solution of the fuzzy system, the lower and upper values may not increase at the same rate.

The technical details of defining the lower and upper boundary matrices are not described here in terms of $l, m$ and $u$ values. For more information, interested read- 
ers may refer to Beynon et al. (2005). It is noteworthy that the technical coefficients for the symmetric case can be expressed in the following form:

$\left.a_{L, \beta, \alpha, i j}=(1-(1-\alpha) \beta) m_{i j}\right)$

$\left.a_{U, \beta, \alpha, i j}=(1+(1-\alpha) \beta) m_{i j}\right)$ and

When dealing with the ranking procedure, different methods display different rank orders (Wang et al, 2006). Beynon et al. (2005) based their work on the formulas described by Chu \& Tsao (2002). However, these ranking formulas are incorrect according to Wang et al. (2006). Thus, the most appropriate method of ranking fuzzy numbers that is consistent with the change in fuzziness of the technical coefficient matrix involves using centroids calculated by formulae due to Wang et al. (2006, p. 921). Moreover, the method based on Euclidean distances from the origin to the centroid points provides a useful and simplified computational application for ranking fuzzy numbers.

The ranking of each fuzzy number is distributed over the $\beta$ domain that ensures a solution, i.e. $\beta_{\max }$ where the general $S($.) area is obtained by:

$S(.)_{\beta}=\bar{a}_{\beta} * \bar{a}_{\beta}^{-1}$

where:

$\bar{a}_{\beta}=\frac{\int_{l}^{m} x \bar{a}_{\beta, L}(x) d x+\int_{m}^{u} x \bar{a}_{\beta, U}(x) d x}{\int_{l}^{m} \bar{a}_{\beta, L}(x) d x+\int_{m}^{u} \bar{a}_{\beta, U}(x) d x}$ and

$\bar{a}_{\beta}^{-1}=\frac{\int_{0}^{1} \alpha \bar{a}_{\beta, U}^{-1}(\alpha) d \alpha-\int_{0}^{1} \alpha \bar{a}_{\beta, L}^{-1}(\alpha) d \alpha}{\int_{0}^{1} \bar{a}_{\beta, U}^{-1}(\alpha) d \alpha-\int_{0}^{1} \bar{a}_{\beta, L}^{-1}(\alpha) d \alpha}$

The main errors arising from Beynon et al's (2005) ranking formulas (see Appendix 1) are due to the second form, i.e. "both numerator and denominator take a positive sign, which is a fundamental error and makes the formulae wrong for any a value" (ibid). Hence, instead of summation, we use subtraction in equation [8].

Consequently, equation [7] combined with equation [8] gives the appropriate rank order for the considered sector, where rank reversal is plausible.

\subsection{THE EIGENVECTOR METHOD}

As indicated in the introduction, the indicators developed by Rasmussen (1956) are used in the linkage analysis performed in Hristov et al. (2012). In the following, we give a brief overview of the method whereby both backward and forward linkages are linked to each other as the result of the properties of the eigenvalues and eigenvectors of nonnegative square matrices, i.e. the Perron-Frobenius theorem (Galanopoulos et al, 2007).

Before deriving the backward and forward linkages in terms of the eigenvector method, it is essential to bear in mind the basic input-output matrix algebra to obtain a better understanding of the associated relationship. Consider a nonnegative square matrix with $n \times n$ flows among sectors $(X)$, where $x$ is the row vector of total inputs (Miller \& Blair, 2009). In addition, let $A$ be the matrix of technical coefficients given by:

$A=X \hat{x}^{-1}$

where $\hat{x}$ denotes a diagonal matrix with the elements of $x$ on the leading diagonal.

If we consider $x$ to be a column vector of total outputs, we can obtain a $B$ matrix of input-output coefficients, i.e:

$B=\hat{x}^{-1} X$

Hence, from equation [9] and [10], we note that $X$ is:

$X=A \hat{x} \quad$ or $X=\hat{x} B$

Therefore, if we assume that $\lambda$ is dominant eigenvalue for the input-output matrix $A$, we can see from the relationship in [11] that matrix $B$ has the same dominant eigenvalue. This implies that:

$A y=\lambda y$

such that $y$ is the non-zero column eigenvector of a matrix $A$.

\subsection{LINKAGES}

Given the Perron-Frobenius theorem, the eigenvector may be interpreted as a quantity vector defined either as a "left hand" or "right hand" Perron vector. Backward linkages are associated with the "left hand" Perron vector, whereas forward linkages are measured by the "right 
hand" Perron vector (Dietzenbacher, 1992). It can be shown that both backward and forward Perron vectors are indeed associated with the dominant eigenvalue of the input and output coefficient matrices.

Thus, given that there is a "left hand" Perron vector $q$, this implies that:

$q^{\prime} A=\lambda q$

where prime indicates transposition. Or:

$A^{\prime}=\lambda q$ since $q^{\prime} A=A^{\prime} q$

The detailed derivation of the backward linkage reflected by the eigenvector is presented in Dietzenbacher (1992). However, it is important to know that the expression given below for the backward linkage indicator (BLI) is derived from equation [14].

$B L I=n q^{\prime} / q^{\prime} e$

with $e$ representing the column summation vector, i.e. $e=1$ for each sector in the $n \times n$ matrix (ibid).

Considering the forward linkage, there exists a "right hand" Perron vector $z$ associated with the matrix of output coefficients $B$. Hence:

$\lambda z=B z$

Considering equation [10], and replacing $X$ with equation [11], the following expression is obtained:

$B=\hat{x}^{-1} A \hat{x}$

which may be substituted in equation [16], i.e:

$\lambda z=\hat{x}^{-1} A \hat{x} z$

Premultiplying expression [18] on both sides with $\hat{x}$, we obtain:

$\hat{x} \lambda z=\hat{x} \hat{x}^{-1} A \hat{x} z \quad$ or $\quad \lambda \hat{x} z=A \hat{x} z$

If we set $y=\hat{x} z$, then equation [19] becomes:

$\lambda y=A y$

which is equivalent to equation [12].

Since we can demonstrate that both $A$ and $B$ have the same dominant eigenvalue $\lambda$, and using the relation- ship $y=\hat{x} z$, it is meaningful to say that the forward linkage indicator (FLI) shows a form similar to BLI, i.e.:

$F L I=n z / a^{\prime} z$

Each element of the two Perron vectors is normalized with respect to their means, which thus allows us to assess the essential or key sectors in a similar manner as in Duarte \& Sánchez-Chóliz (1998), i.e. a sector is considered as key when the estimates of its indicators are above average, i.e. greater than 1 .

In our analysis, we should be aware that the Macedonian symmetric input-output matrix is not diagonaldominant but, considering this problem apart, the Dietzenbacher framework works well.

\section{RESULTS AND DISCUSSION}

This section provides an analogous analysis of the input-output relationship in Macedonia in terms of water consumption. Again, we are dealing with a 28 -sector symmetric input-output table for 2005 as published by the State Statistical Office (2008). A list of the sectors is given in Table 1. As mentioned in the introduction, the 59 sectors initially included had to be aggregated due to some absent data on water consumption, yielding a final list of 28 sectors. Hence, beside the uncertainty of the selected data in terms of water use, the aggregation of sectoral primary factor returns is an additional source of uncertainty and imprecision in our input-output analysis. Therefore, we apply a fuzzy approach to the technical coefficients of the symmetric 28-sector input-output matrix to investigate whether there are any changes in the level of fuzziness given the imposed aggregation. Based on the above technical details, we can define the domain of $\beta$ that ensures a solution to the fuzzy input-output models:

$\beta_{\max }=\min (1,1.231,7.977,1.488,1.213,0.598$, $8.923,0.473,1.315,3.16,1.637,4.556,0.412,5.342$, $2.323,1.809,1.086,1.44,7.854,3.658,13.272,7.078$, $4.023,2.743,1.038,1.197,2.511,0.597,1.522)=0.412$

Hence, a value of 0.412 limits the analysis for the 28-sector input-output model. As indicated above, an upper bound of 1 is not a strict general condition in a fuzzy environment.

Figure 2 shows the fuzzification structure of the output multipliers for the key water consuming sectors found in Hristov et al. (2012). The output multipliers for all sectors are reported in Table 1 . The results of the adopted fuzzification of the input-output matrix of technical coefficients indeed display a variation in the level of fuzziness for some output multipliers as $\beta$ varies from 
Table 1: Results from the previous study as well as Dietzenbacher backward (BLI) and forward linkages (FLI) indices in terms of water consumption

Preglednica 1: Rezultati predhodne študije in indikatorji Dietzenbacherjevih predhodnih (BLI) in prihodnjih povezav (FLI) pri porabi vode

\begin{tabular}{|c|c|c|c|c|c|c|c|}
\hline \multirow[b]{3}{*}{$\mathrm{Nr}$} & \multirow[b]{3}{*}{ Sectors } & \multirow{3}{*}{$\begin{array}{l}\text { Output } \\
\text { multipliers }\end{array}$} & \multirow{3}{*}{$\begin{array}{l}\text { Indicator of } \\
\text { total water use } \\
\text { per one mil- } \\
\text { lion of output } \\
\left(\mathrm{m}^{3}\right)\end{array}$} & \multicolumn{4}{|c|}{ Linkage indicators } \\
\hline & & & & \multicolumn{2}{|c|}{ Rasmussen } & \multicolumn{2}{|c|}{ Dietzenbacher } \\
\hline & & & & BLI & FLI & BLI & FLI \\
\hline 1 & Agriculture, forestry and fisheries & 1.734 & 5833.81 & 1.97 & 5.59 & 5.31 & 1.75 \\
\hline 2 & Mining and quarrying & 1.182 & 5821.57 & 0.06 & 0.52 & 4.98 & 12.30 \\
\hline 3 & Other mining and quarrying products & 1.669 & 8168.99 & 2.16 & 3.89 & 8.12 & 9.35 \\
\hline 4 & Food products and beverages & 1.772 & 4109.67 & 2.40 & 0.86 & 2.86 & 0.31 \\
\hline 5 & Tobacco products & 2.141 & 2786.31 & 3.15 & 0.02 & 0.07 & 0.00 \\
\hline 6 & Textiles & 1.134 & 82.87 & 0.02 & 0.06 & 0.02 & 0.00 \\
\hline 7 & Wearing apparel; furs & 1.916 & 195.78 & 0.04 & 0.01 & 0.04 & 0.00 \\
\hline 8 & Leather and leather products & 1.737 & 160.25 & 0.03 & 0.01 & 0.01 & 0.00 \\
\hline 9 & $\begin{array}{l}\text { Wood and products of wood and cork (except } \\
\text { furniture); articles of straw and plaiting materials }\end{array}$ & 1.391 & 1282.24 & 0.85 & 0.25 & 0.57 & 0.23 \\
\hline 10 & Pulp, paper and paper products & 1.619 & 229.08 & 0.04 & 0.12 & 0.01 & 0.03 \\
\hline 11 & Printed matter and recorded media & 1.267 & 237.64 & 0.04 & 0.07 & 0.01 & 0.10 \\
\hline 12 & $\begin{array}{l}\text { Coke, refined petroleum products and nuclear } \\
\text { fuels }\end{array}$ & 1.854 & 3937.40 & 7.56 & 2.24 & 0.01 & 0.01 \\
\hline 13 & $\begin{array}{l}\text { Chemicals, chemical products and man-made } \\
\text { fibres }\end{array}$ & 1.221 & 397.57 & 0.19 & 1.30 & 0.20 & 0.25 \\
\hline 14 & Rubber and plastic products & 1.417 & 159.90 & 0.09 & 0.09 & 0.15 & 0.01 \\
\hline 15 & Other non-metallic mineral products & 1.605 & 1330.13 & 1.00 & 0.09 & 0.17 & 0.06 \\
\hline 16 & Basic metals & 1.790 & 2838.12 & 1.63 & 2.60 & 1.88 & 1.12 \\
\hline 17 & $\begin{array}{l}\text { Fabricated metal products, except machinery } \\
\text { and equipment }\end{array}$ & 1.720 & 992.07 & 0.93 & 0.04 & 0.02 & 0.01 \\
\hline 18 & Machinery and equipment & 1.194 & 628.53 & 0.23 & 0.30 & 0.33 & 0.15 \\
\hline 19 & $\begin{array}{l}\text { Office, computers; Electrical machinery and } \\
\text { apparatus; Radio, TV, communication }\end{array}$ & 1.362 & 3328.22 & 0.43 & 0.19 & 2.90 & 2.14 \\
\hline 20 & $\begin{array}{l}\text { Medical, precision and optical instruments, } \\
\text { watches and clocks }\end{array}$ & 1.093 & 28.42 & 0.01 & 0.00 & 0.00 & 0.00 \\
\hline 21 & Motor vehicles, trailers and semi-trailers & 1.217 & 316.32 & 0.28 & 0.01 & 0.02 & 0.00 \\
\hline 22 & Other transport equipment & 1.351 & 594.64 & 0.45 & 0.00 & 0.08 & 0.00 \\
\hline 23 & Furniture; other manufactured goods & 1.378 & 170.78 & 0.06 & 0.05 & 0.07 & 0.06 \\
\hline 24 & Secondary raw materials & 1.824 & 859.30 & 0.75 & 0.07 & 0.00 & 0.01 \\
\hline 25 & Electrical energy, gas, steam and hot water & 1.635 & 1497.27 & 2.41 & 1.56 & 0.07 & 0.06 \\
\hline 26 & $\begin{array}{l}\text { Collected and purified water, distribution serv- } \\
\text { ices of water }\end{array}$ & 1.430 & 505.95 & 0.42 & 0.04 & 0.00 & 0.00 \\
\hline 27 & Construction work & 2.095 & 1076.58 & 0.57 & 0.04 & 0.04 & 0.00 \\
\hline 28 & Services & 1.639 & 459.90 & 0.24 & 7.97 & 0.04 & 0.01 \\
\hline
\end{tabular}




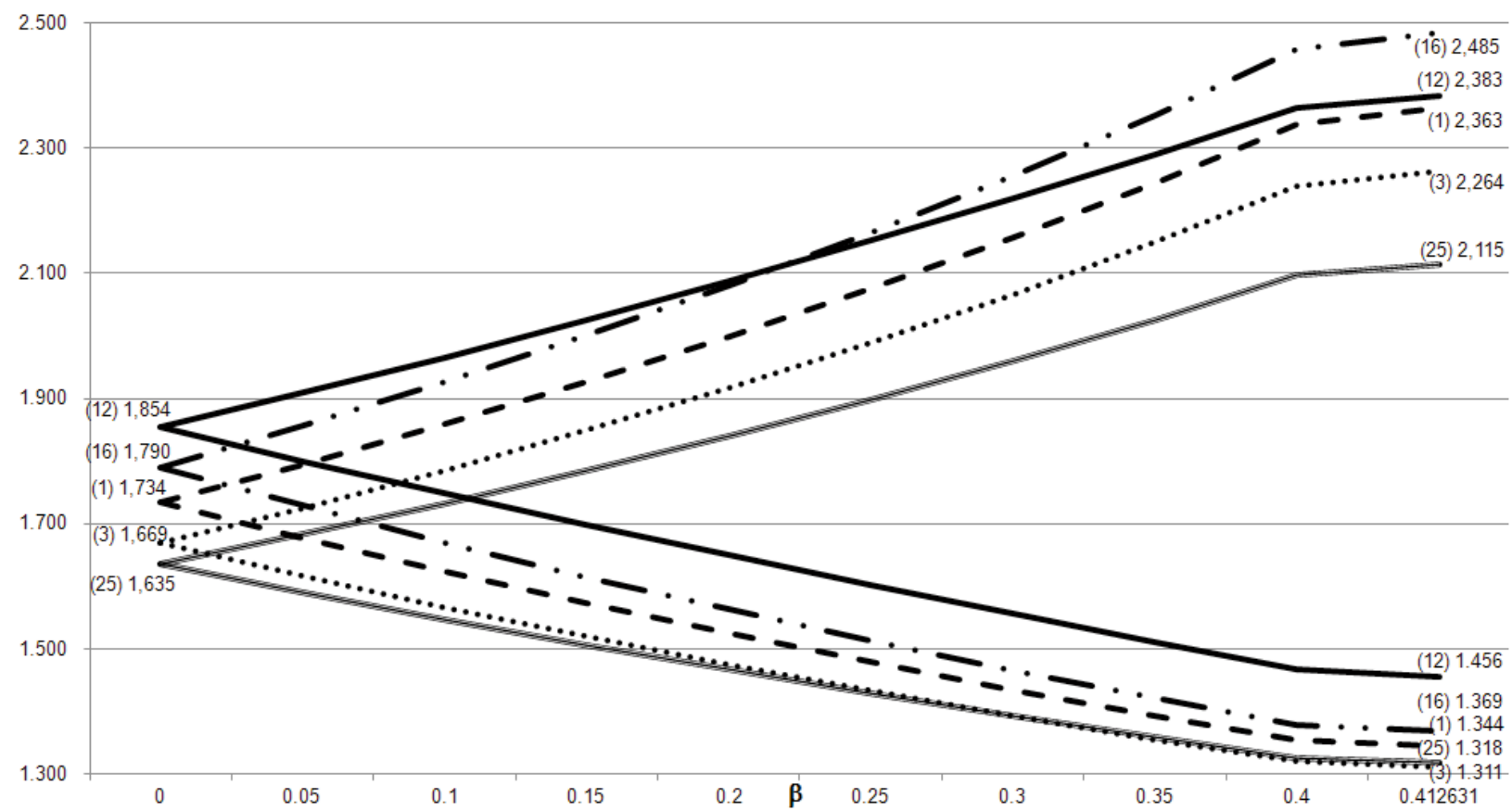

Figure 2: Bounds on the fuzzy triangular output multipliers for the key water consuming sectors given in Hristov et al. $(2012)$ for $0<\beta<0.412$ Slika 2: Povezave fuzzy trikotnih izhodnih pomnoževalcev za glavne sektorje porabe vode (Hristov in sod., 2012) za $0<\beta<0,412$

0 to the level that ensures a solution. Considering the sectors coke and refined petroleum (12) as well as base metals (16), when the level of uncertainty is increased, a change appears in their upper rate when $\beta$ is around 0.2 In addition, the electrical energy (25) sector changes the level of fuzzification with the other mining (3) sector in their lower bounds when $\beta$ is around 0.3.

Due to space limitations, we do not report the results of the lower and the upper bounds of the fuzzy triangular output multipliers for all 28 sectors, but this information is available upon request. However, at this stage, for almost all output multipliers, we find that the rate of change for the upper and the lower values is not stable, i.e. the triangle is not symmetric even though the general symmetry approach is applied. Consequently, this means that when the sectors are ranked in a fuzzy environment, there will be changes in the ranking order given the proportional imprecision, i.e. rank reversal. However, since we are more interested in investigating the water consumption in terms of the indicator of total water consumption provided in Table 1, we continue our analysis by omitting the ranking methodology of the output multipliers. In the same way as with the Leontief output multipliers, the indicators of total water consumption is a row vector expressing the total amount of water that the economy will consume, both directly and indirectly, if there is a unit increase in any given sector.

The reasons given by Hristov et al. (2012) for being hesitant in identifying key water consumption sectors are confirmed in the fuzzy environment of the technical coefficients. The changes in the degree of fuzzification affect the Rasmussen linkage analysis, since the direct (inputoutput) technical coefficient matrix is linked to the identification methodology.

Therefore, in our study, we apply the Dietzenbacher eigenvector method to the non-fuzzy input-output matrix in terms of water consumption. Table 1 reports the results of this analysis.

Given that the eigenvector method is considered as superior, providing a better indicator of interindustry linkages compared with the Rasmussen framework, the obtained results may be considered as robust. Table 1 shows that, based on the new linkage analysis, new sectors can be considered as key in terms of water use. The sectors of agriculture (1), other mining (3) and base metals (16) maintain their position as major water users, but now the mining (2) and production of electrical machinery and related equipment (19) sectors are included in this group. These results are realistic since all these sectors in the previous study obtained the largest indicators of direct water consumption per currency unit produced output, and consequently the largest indicators of total water use per unit of output produced (Table 1). This implies that these sectors have a crucial influence on the limited Macedonian water resources. Moreover, in the water transaction matrix (see appendix 2), these sectors are the most considered in the intersectoral water relationships. 


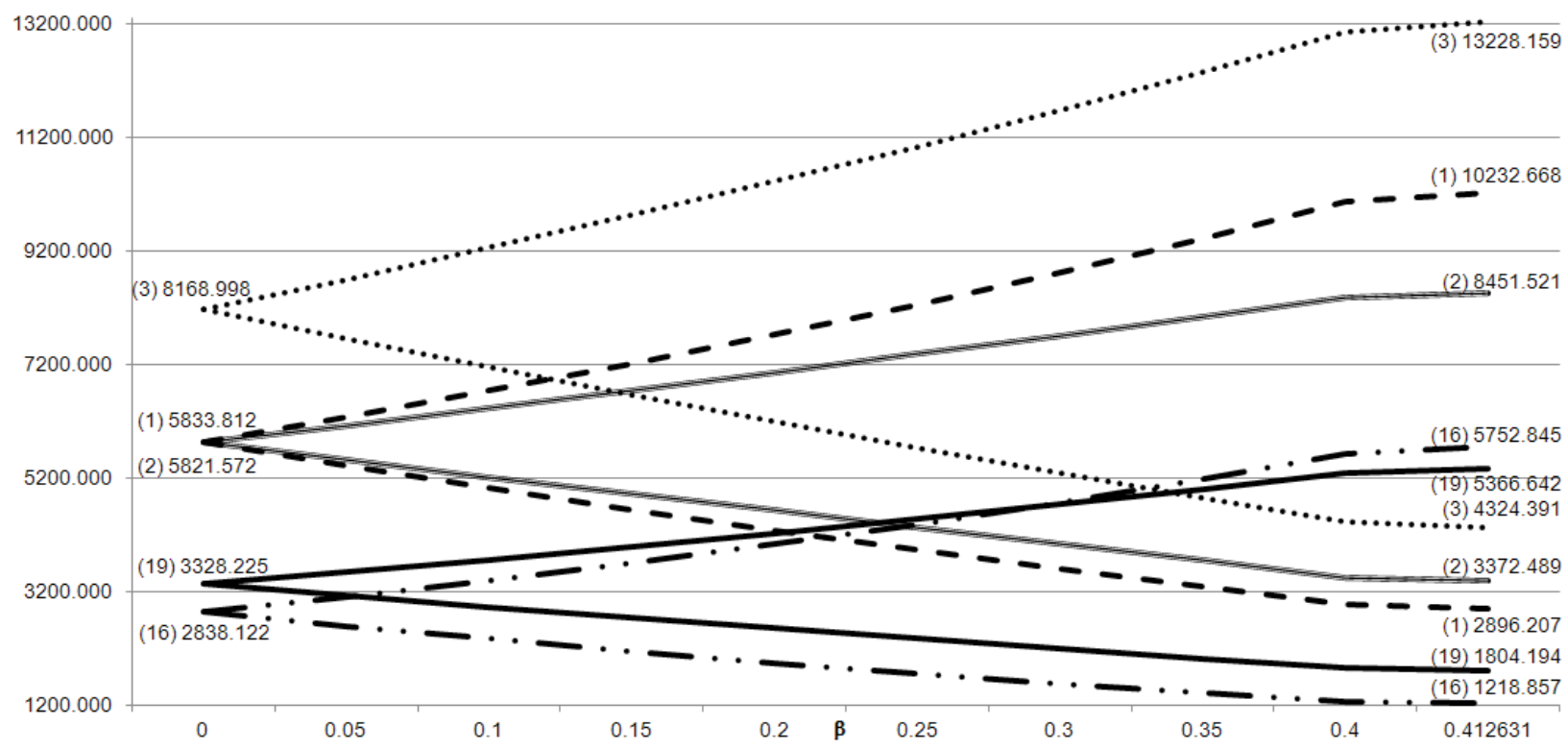

Figure 3: Bounds of the triangular fuzzy indicators of total water consumption for the key water consuming sectors determined using the eigenvector method, for $0<\beta<0.412$

Slika 3: Povezave fuzzy trikotnih indikatorjev za skupno porabo vode za glavne sektorje porabe vode $z$ metodo eigenvektorjev za $0<\beta<0,412$

Because of these new perspectives arising from our analysis, we are keener to investigate and apply the proposed fuzzy methodological framework to the water composition coefficients. As we indicated above, the main reason is that we are uncertain about the data used concerning the direct total water consumption. Consequently, the uncertainty and imprecision can be reduced by analysing the intensive water consumption in Macedonia using a fuzzy perspective.

Similarly as described previously, we focus our analysis only on the key water use sectors found by the eigenvector methodology, using the same domain that ensures a solution to the fuzzy input-output model. Figure 3 shows the bounds of the triangular fuzzy indicators of total water consumption for the key water consuming sectors. Again, due to limited space, the bounds for the 28 sectors are omitted, but may be obtained on request from the corresponding author.

From Figure 3, as in the case of the output multipliers, we can see that there are changes in the level of fuzziness for the new key water use sectors identified by the Dietzenbacher method. Agriculture (1) and other mining (3) display a steady increase in the level of fuzziness. By contrast, the base metals (16) and electrical energy (19) sectors exhibit changes in their upper value of water consumption when the level of imprecision is around 0.3 . As the imprecision increases to a level that ensures solution of the fuzzy system, the lower and upper values of consumption do not increase at the same rate. This is visible in Figure 4, which shows the fuzzy triangular membership functions of the respective sectors plotted against the $\alpha$ and $\beta$ parameters. The larger the value of the indicator, the greater the uncertainty. Therefore, in the final step of the analysis, where we apply the ranking of each fuzzy triangular water indicator, we would expect to observe rank reversal for the sectors that display changes in their level of fuzzification.

As indicated in the methodological framework section, we decided to implement the ranking formulas of Wang et al. (2006) as being the most appropriate procedure for the ranking of fuzzy numbers which is consistent with the change in fuzziness level. Indeed, by examining Figure 5, we note that there are changes in the ranking of the base metals sector (16) and the sector responsible for electrical equipment production (19). Rank reversal appears at a fuzzy level of around 0.35 , which is consistent with the analysis derived from Figs. 3 and 4. However, this may be a consequence of the imposed general symmetry condition. This implies that the value of the indicator increases with the expected associated level of variance, since there is an increase in uncertainty and imprecision. Hence, we may conclude from this analysis that, in a fuzzy environment, agriculture remains the key water consuming sector, associated with high indicators of direct and total water consumption. In addition to ranking the other key water use sectors identified by the Dietzenbacher method, our analysis in terms of a fuzzy environment is also consistent with the heavy 


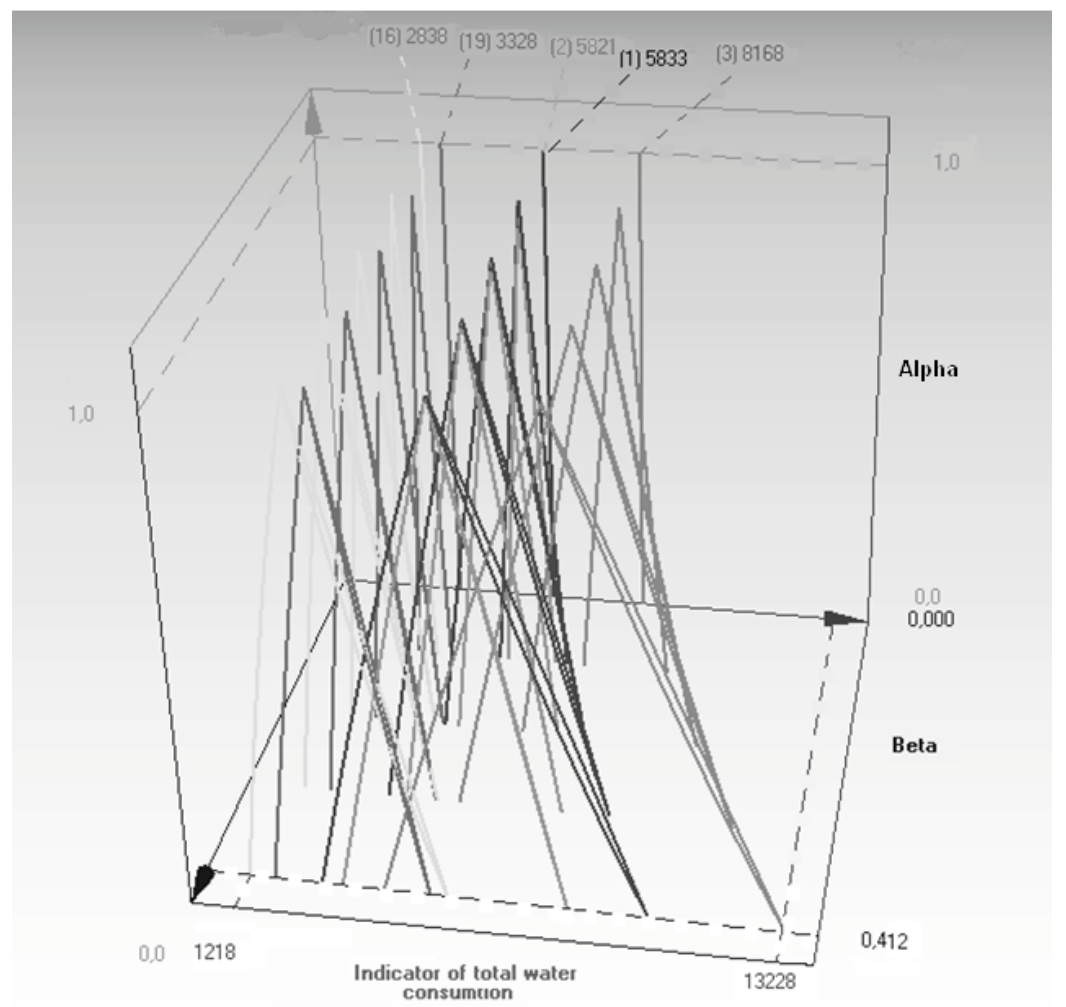

Figure 4: 3-D representation showing triangular fuzzy set membership functions of the indicators of total water consumption of the key sectors plotted against $\alpha$ and $\beta$

Slika 4: Fuzzy trikotna vključitvene funkcije za indikatorje skupne porabe vode po sektorjih kot funkcija $\alpha$ in $\beta$

exploitation of water resources by industrial sectors in Macedonia. Therefore, due to the high indicator of total water consumption, increases in the production of these sectors will impose a significant pressure on the natural freshwater resources and the environment.

Clearly, by combining the fuzzy environment with the Dietzenbacher method, we are able to reduce the uncertainty and imprecision of the input-output analysis of water consumption in Macedonia. In addition, the applied ranking method provides us with a tool to consider whether or not policy options should be targeted at this natural resource. As proposed in Hristov et al. (2012), we confirm that the water-intensive structure is mainly focused around agriculture and several industrial sectors, given the fact that rank reversal is absent. Consequently, there is a need to introduce changes in the technology and specialization of agricultural production in this region, or maybe policy makers should carefully reconsider the existing water pricing policy.

In the following, we discuss some aspects that might be considered in our analysis as well as the arguments that underlie the limitation of these frameworks.

By defining a Beta probability distribution that best fits the direct technical coefficients (Diaz \& Morillas,
2011), it would be more appropriate to use a methodological framework based on stochastic analysis through Monte Carlo simulations. Although the Beta probability distribution allows for higher flexibility and defines the domain of the input-output coefficients with only two parameters, it is impossible to apply in the present study because its implementation requires a wealth of prior data. Indeed, defining a Beta probability distribution requires prior information (primary data obtained from the firm surveys used to construct the symmetric input-output table) which are not at our disposals at the moment. Hence, due to this inconvenience, we adopt the general symmetry approach even though $l$ underestimates and $u$ tend to overestimate with respect to true observed value.

The Dietzenbacher method is only applied here to the non-fuzzy matrix in terms of water consumption because of limitations in the method developed by Buckley (1990) to find fuzzy eigenvalues for a given fuzzy matrix $\bar{A}$. It is limited in the sense that the necessary requirement to ensure a solution in $\bar{\lambda} \bar{y}=\bar{A} \bar{y}$ is $\bar{\lambda} \geq 0$ and $\bar{y} \geq 0$ should satisfy the same criteria as the positive elements in $\bar{A} \geq 0$. "When $\bar{\lambda}<0$ the equations to solve for the fuzzy eigenvalue are far more complicated and there is no guarantee that their solution will produce a bona fide fuzzy 


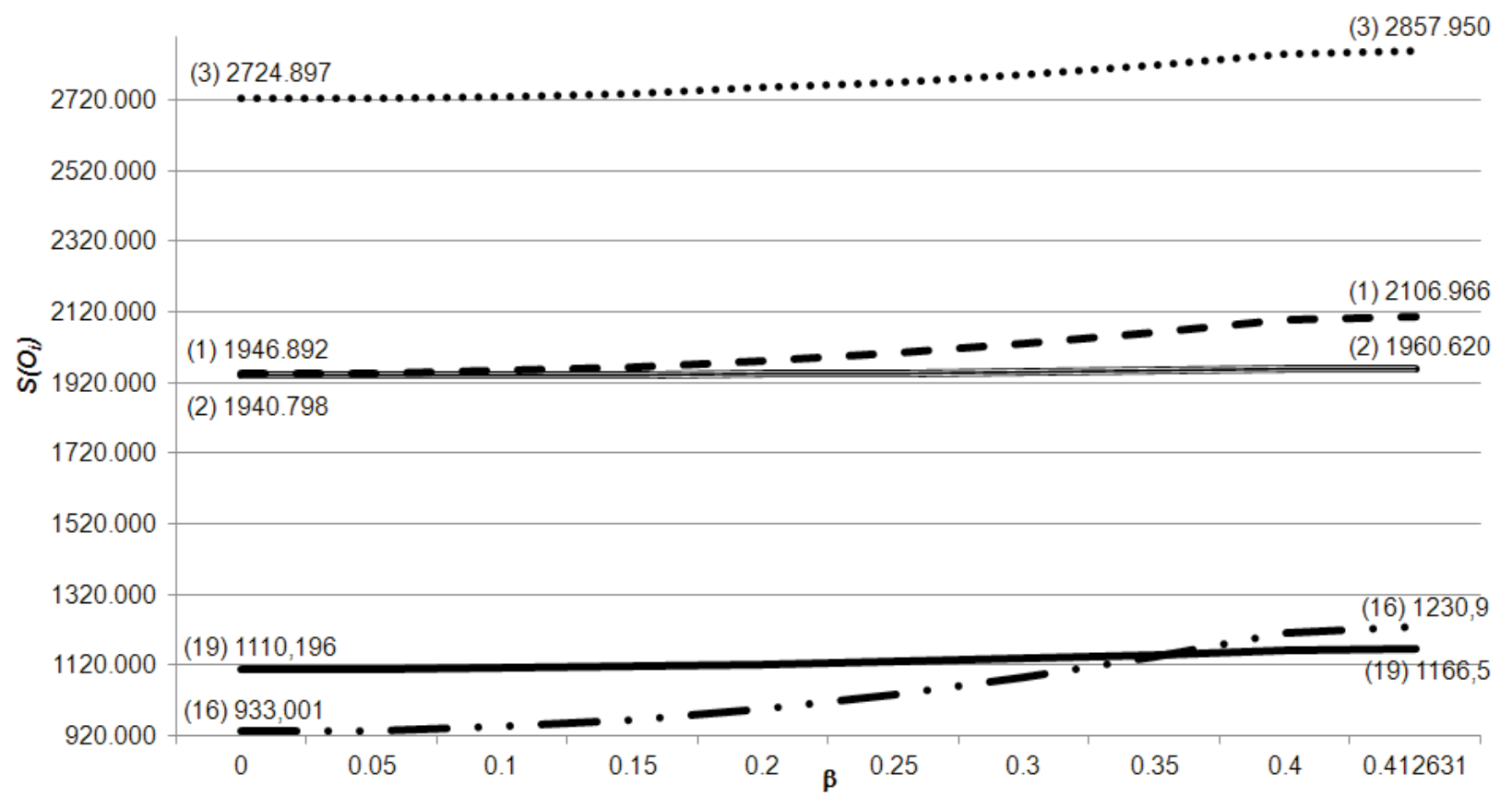

Figure 5: Ranking of the key water consuming sectors for $0<\beta<0.412$ Slika 5: Rangiranje glavnih sektorjev porabnikov vode za $0<\beta<0,412$

number for $\bar{\lambda}$ " (Buckley, 1990, p. 193). Given that our symmetric input-output matrix is not diagonally dominant, we may argue that it is plausible to obtain a negative eigenvalue in fuzzy analysis. Hence, the eigenvector method was omitted in the fuzzy environment.

\section{CONCLUSION}

In this paper, we take account of the imprecision and uncertainty inherent in the data used for constructing input-output tables or extending the classical Leontief relationship in terms of environmental indicators, which are followed by problems caused by aggregation of some sectors. Fuzzy modelling allows us to investigate the effects of uncertainty on the technical coefficients of the symmetric input-output table and the indicators of total water consumption in Macedonia. By imposing triangular membership functions and general symmetric imprecision, we are able to achieve greater transparency for the unreliable/suspect results proposed in Hristov et al. (2012) in terms of identification of the key water use sectors. We confirm that Dietzenbacher's method is better than Rasmussen's in terms of identifying key sectors, irrespective of the considered aspect (environmental, monetary, etc.). The Dietzenbacher eigenvector method as applied here suggests that agriculture and several industrial sectors impose heavy exploitation on the limited water resources in Macedonia. In addition, ranking of each fuzzy triangular water indicator does not lead to rank reversal for most of these sectors. Although two sectors exhibit rank reversal at a high level of imprecision and uncertainty, this may be related to the initially imposed general symmetric imprecision. Simply stated, the larger the fuzzy number, the larger the expected associated variation.

Therefore, we may conclude that, in general, it is necessary to propose changes in the technology or specialization of production in this region. Another option is to reconsider the existing water pricing policy in Macedonia.

The most important contribution of this study is that it represents the first attempt to apply such a methodology in the western Balkans, not just in terms of conventional monetary input-output analysis but also in terms of ecological footprints. Most of the existing literature is focused either on the United Kingdom (including Wales) or the Andalusia region in Spain (Beynon et al. (2005), Beynon \& Munday (2007), Diaz \& Morills (2011), Morillas et al. (2011)). Moreover, another significant difference with Beynon's work is our application of the correct centroid formulas described by Wang et al. (2006) to rank the fuzzy numbers.

By reducing the uncertainty in the obtained results, we highlight a new approach for future research that may further raise the awareness of this natural resource. This 
approach, which involves disaggregation of agriculture into major water consuming sectors, could be of even greater importance in determining policy options for sustainable water management and potential water pricing policies. The end result of this extension will be a detailed and disaggregated input-output table for the Macedonian economy with a special emphasis on agriculture. Another idea that emerges from this fuzzy approach is to create detailed water accounts similar to those published by the Australian Bureau of Statistics (2010). In that sense, there would be no need of a fuzzy approach since the exact relationship (supply and demand) between sectors will be known. Moreover, the establishment of detailed water accounts may serve to create a symmetric input-output table in terms of water consumption. This is an aspect that policy makers should really focus on in the future!

\section{REFERENCES}

Australian Bureau of Statistics. 2010. Water Account Australia 2008-09. Catalogue no. 4610.0. Canberra

Buckley J.J. 1989. Fuzzy input-output analysis. European Journal of Operational Research, 39: 54-60

Buckley J.J. 1990. Fuzzy eigenvalues and input-output analysis. Fuzzy set and systems, 34: 187-195

Beynon M.J., Munday M. 2006. The elucidation of multipliers and their moments in fuzzy closed Leontief input-output systems. Fuzzy sets and systems, 157: 2482-2494

Beynon M.J., Munday M. 2007. An aggregated Regional Economic Input-Output Analysis within a Fuzzy Environment. Spatial Economic Analysis, 2, 3: 281-296

Beynon M.J., Munday M. 2008. Considering the effects of imprecision and uncertainty in ecological footprint estimation: An approach in fuzzy environments. Ecological Economics, 67: 373-383

Beynon M.J, Munday M., Roberts A. 2005. Ranking sectors using fuzzy output multipliers. Economic System Research, 17: 237-253

Cao B-Y. 2010. Optimal Models \& Methods with Fuzzy Quantities. Studies in Fuzziness and Soft Computing, 248: 95-115
Chu T., Tsao C. 2002. Ranking fuzzy numbers with an area between the centroid point and original point. Computers and Mathematics with Applications, 43: 111-117

Diaz B., Morillas A. 2011. Incorporating uncertainty in the coefficients and multipliers of an IO table: A case study. Papers in Regional Science, 90, 4: 845-861

Diaz B, Moniche L., Morillas A. 2006. A fuzzy clustering approach to the key sectors in the Spanish economy. Economic System Research, 18, 3: 299-318

Dietzenbacher E. 1992. The measurement of inter-industry linkages: Key sectors in the Netherlands. Economic Modelling, 9: 449-437

Duarte R., Sanchez-Choiliz J., Bielsa J. 2002. Water use in the Spanish economy: an input-output approach. Ecological Economics, 43: 71-85

Duarte R., Chóliz S.J. 1998. Regional Productive Structure and Water Pollution: An Analysis using the Input-Output Model. In: 38th Congress of The European Regional Science Association, August-1st September. Vienna, European Regional Science Association

Galanopoulos K., Lindberg E., Nilsson F., Surry Y. 2007. Agricultural Situation Synthesis Report. MEDFROL project FP6-2002-SSP-1, Market and Trade Policies for Mediterranean Agriculture: The case of fruit/vegetables and olive oil

Hristov J., Martinovska-Stojceska A., Surry Y. 2012. Input-Output analysis for water consumption in Macedonia. Working paper presented at the European Summer School in Resource and Environmental Economics: Management of International Water, 1-7 July 2012. Venice, Italy

Miller R.E., Blair P.D. 2009. Input-output analysis. Foundations and extensions. Cambridge, Cambridge University Press. Second edition

Morillas A., Robles L., Diaz B. 2011. I-O coefficients importance: A fuzzy logic approach. International Journal of Uncertainty, Fuzziness and Knowledge-Based Systems, 19, 6: 1013-1031

Rasmussen P.N. 1956. Studies in Intersectoral Relations. Amsterdam, North-Holland

State Statistical Office. Symmetric Input-Output table for the Republic of Macedonia, 2005, November, 2008, Skopje

Wang Y.M, Yang J-B, Xu D-L., Chin K-S. 2006. On the centroids of fuzzy number. Fuzzy Sets and Systems, 157: 919-926

Zadeh L.A. 1965. Fuzzy sets. Infromation and Control, 8: 338-353

\section{APPENDICES}

Appendix 1: Ranking formulas applied in Beynon et al. (2005)

Priponka 1: Formule za rangiranje po Beynon in sod. (2005)

$$
S_{\beta}=\bar{a}_{\beta} * \bar{a}_{\beta}^{-1}=\frac{\int_{l}^{m} x \bar{a}_{\beta, L}(x) d x+\int_{m}^{u} x \bar{a}_{\beta, U}(x) d x}{\int_{l}^{m} \bar{a}_{\beta, L}(x) d x+\int_{m}^{u} \bar{a}_{\beta, U}(x) d x} * \frac{\int_{0}^{1} \alpha \bar{a}_{\beta, L}^{-1}(\alpha) d \alpha+\int_{0}^{1} \alpha \bar{a}_{\beta, U}^{-1}(\alpha) d \alpha}{\int_{0}^{1} \bar{a}_{\beta, L}^{-1}(\alpha) d \alpha+\int_{0}^{1} \bar{a}_{\beta, U}^{-1}(\alpha) d \alpha}
$$




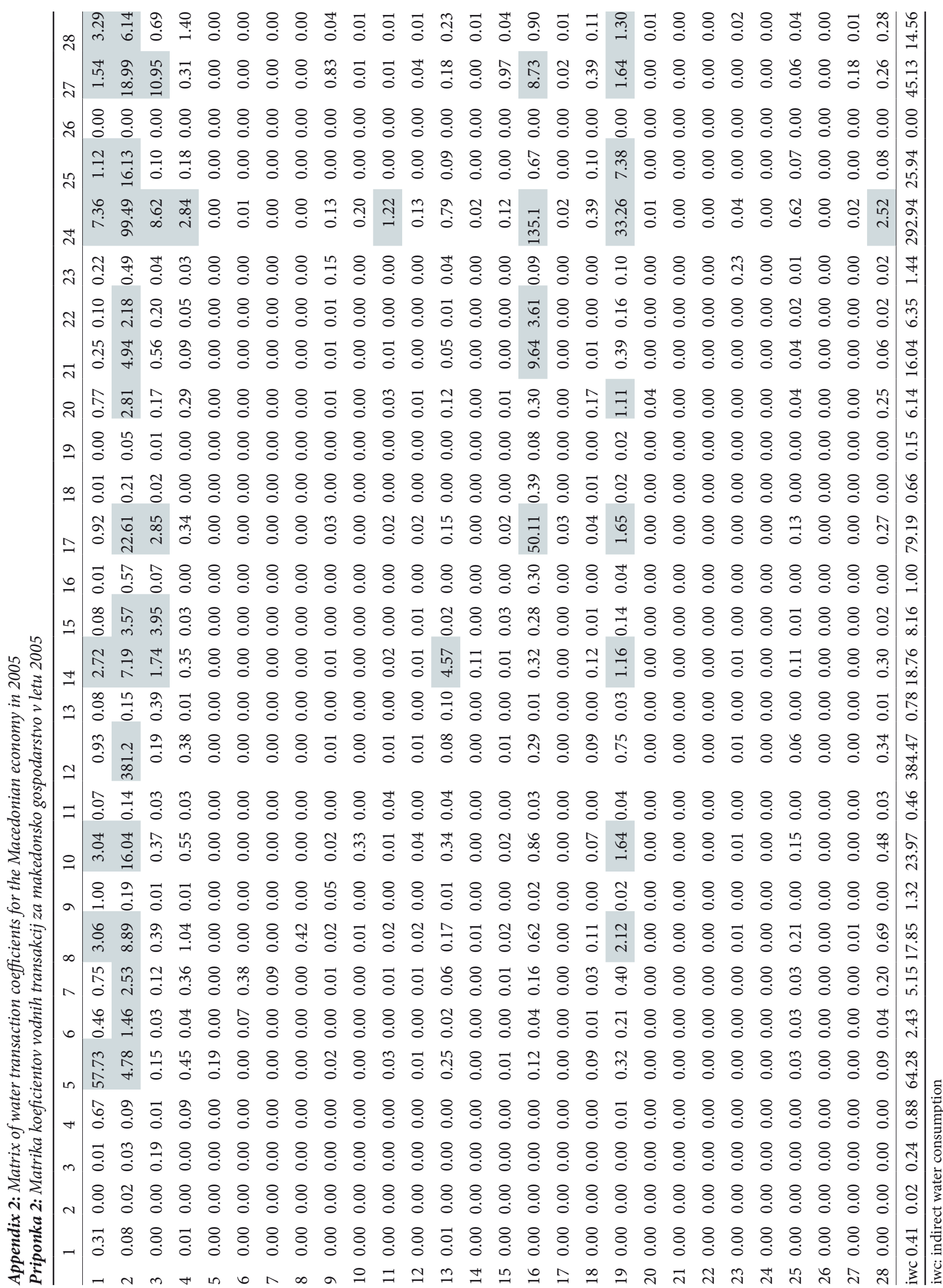

